\title{
PERFECT BEING THEOLOGY AND MODAL TRUTH
}

\author{
Jeff Speaks
}

\begin{abstract}
In "The Method of Perfect Being Theology," I argued that the attempt to derive the divine attributes from the principle that God is the greatest possible being faces substantial challenges. Here I clarify and defend the argument of that paper in response to the objections of Brian Leftow in "Perfection and Possibility," and consider the question of whether we might use perfect being reasoning to establish the possibility of certain hypotheses about God.
\end{abstract}

Perfect being theology is the attempt to use the principle that God is the greatest possible being to derive claims about the divine attributes. Roughly, the idea is that, for some property F, if God would be greater if $\mathrm{F}$ than if not $\mathrm{F}$, then, given that God is the greatest possible being, God must be F.

This method is very widely deployed in contemporary philosophical theology. One prominent instance can be found in BrianLeftow's God and Necessity, in which this method is used to argue for, among other things, the following principle:

NEC. $(\mathrm{P})(\square \mathrm{P}$ is true $\rightarrow$ God is, contains, has, has attributes that have (etc.) or produces all its truth-explainers) ${ }^{1}$

The argument is that, as Leftow says, "It would be an awesome thing to be unconstrained even by modal truths and facts of modal status ... A being whose power is not externally limited even by these would seem more powerful than one whose power was subject to such a constraint." ${ }^{2}$ Suppose that this is correct. It seems to follow that were NEC true, God would be greater than if NEC were false; and this, together with the claim that God is the greatest possible being, seems to entail that NEC is true.

In an earlier paper $^{3} \mathrm{I}$ argued that this form of argument, while intuitively quite plausible, fails, and that the principle that God is the greatest possible being cannot be used in the envisaged way to derive claims about the divine attributes. Leftow offered a reply on behalf of the perfect being theologian. ${ }^{4}$ In this paper, I aim to do three things: (i) clarify and defend

${ }^{1}$ Leftow, God and Necessity, 115.

${ }^{2}$ Leftow, God and Necessity, 134.

3Speaks, "The Method of Perfect Being Theology."

${ }^{4}$ Leftow, "Perfection and Possibility." 
my original argument; (ii) show that, contra Leftow, we cannot defend the argument for NEC via a "perfect being" argument for its possibility; and (iii) present some general problems for the attempt to use "perfect being" considerations as tests for the possibility of various hypotheses about God.

\section{The Basic Problem for Perfect Being Theology, and Leftow's Reply}

Following the numbering in Leftow's 2015 paper, the form of argument characteristic of perfect being theology can be presented as follows:

1. God $=$ that than which no greater is possible.

6. If God can be F, and God would if F be greater than if not F, then God is F. (from 1)

7. God can be F.

8. God would if $\mathrm{F}$ be greater than if not $\mathrm{F}$.

9. God is F. (from $6,7,8$ )

The relevant instance of the argument substitutes "explains the modal truths" for "is F." In what follows I'll be focusing on this instance of the perfect being theologian's argument; most of what I have to say, however, will generalize to other instances of this form of argument.

In "The Method of Perfect Being Theology" I objected to this sort of argument by pointing out that it is plausible that God is not only the greatest possible being, but also necessarily the greatest possible being. That is, it is plausible that (1) is not just true, but necessary. (This seems especially hard for the perfect being theologian to deny, since it seems better to necessarily be the greatest possible being than to be merely contingently so. ${ }^{5}$ ) Given this, the claim that God is F-in our case, the claim that God explains the modal truths - will be necessary if possible.

For suppose that (7) is true, but that (9) is not necessary. Then there would be some world in which God is not F and, given our reasoning about F, this would imply that, in that world, God was less than the greatest possible being. And that contradicts our assumption that (1) is not just true, but necessary. ${ }^{6}$

The problem, though, is that this means that (9) follows from (7) alone. And, if this is true, this seems to make the "greatest possible being" bit of the argument an idle wheel.

\footnotetext{
${ }^{5}$ This seems quite difficult to deny for properties like the property of explaining the necessary truths. But it may not be true for all candidate divine attributes. Some have thought, for example, that moral perfection entails the possibility of doing wrong. If this is right, then it is impossible to be essentially morally perfect, and the perfect being theologian will presumably hold that God is the greatest possible being, but only contingently so. This is a minority view, and would seem to apply to only a few of the divine attributes; but I mention this as a possible limitation on the generality of the present line of objection to perfect being theology. Thanks to Mark Murphy for this point.

${ }^{6}$ This line of thought also assumes that (8) is necessary is possible which, at least in the present case, is a safe assumption.
} 
Leftow's first reply to this objection is that, even if the objection is correct, it does not show that perfect being reasoning can play no role deriving claims about the attributes of God:

Suppose that Speaks is right, and we've now learned that any reason we have to believe (7) is reason to believe (9). It is perfect being reasoning that has shown us this. So perfect being theology is not otiose in our coming to believe (9). It is precisely what tells us that our (7)-reasons are (9)-reasons. Any valid argument tells us that reasons for its premises are reasons to embrace its conclusion. In the dilemma, Speaks in effect holds our reasons to endorse [the claims that God is the greatest possible being and that God would be greater if NEC were true than if it were false] steady, and focuses on our reasons for (7) as making the decisive difference vis- a-vis (9). That's fine. But that one can do that hardly shows that the rest of the argument makes no contribution to our accepting (9).

This is in a way fair enough: it is indeed the necessitation of (1), together with (8), which shows us that (7) is necessary if possible. But that correct point does not show that the claim that God is the greatest possible being gives us, for all that has been said, any reason to believe, or even increase our credence in, (9).

The necessitation of (1), after all, shows not just that (7) is necessary if possible; it also shows us that

$7^{*}$. God is not F.

is necessary if possible. After all, if God would be less great if not $\mathrm{F}$ than if $\mathrm{F}$, and it is possible that God is not $\mathrm{F}$, this must be because the proposition that God is F is impossible. (Otherwise, it would be possible for God to be less than the greatest possible being, which would contradict the necessitation of (1).)

So suppose we are considering the claims that God is F and that God is not F. If it is true that God would be better if $\mathrm{F}$ than if not F, perfect being reasoning tells us that both the claim that God is F and the claim that God is not $\mathrm{F}$ are necessary if possible. But that fact alone hardly helps us to decide whether God is F or God is not F.

Imagine, for comparison, a mathematician wondering whether Goldbach's conjecture or its negation is true. It will not help him to be told that both the conjecture and its negation are, if possible, necessary. Indeed, this new information is unlikely to cause him to adjust his credence in the two mathematical claims. Just so, I think, even if we accept the claim that God is necessarily the greatest possible being and accept some comparative claim of the form of (8), these give us no reason to raise our credence at all in the relevant claim about God. This sort of perfect being reasoning does not move the needle.

This is not, of course, to deny that arguments for the claim that a given proposition is necessary if possible are sometimes of philosophical

${ }^{7}$ Leftow, "Perfection and Possibility," 426. 
significance. For example, Kripke's defense of the Cartesian premise that if it is possible that mind and body be distinct, then they necessarily are, is of great philosophical significance. ${ }^{8}$ But that is because it comes packaged with a plausible conceivability argument for the relevant possibility claim. In the present case, we have no such thing.

\section{From Perfection to Possibility?}

So let's turn to Leftow's second line of reply to my objection to perfect being theology. This reply is more speculative, and is offered more tentatively. The central idea is that perfect being arguments might be used, not just to arbitrate between various hypotheses about God, but also to establish the possibility of certain such hypotheses. Given the problem just identified, this would, if successful, be of great importance.

Leftow's idea is that the proposition that God is F is possible if the following two conditions are met:

(i) The conjunction of $<$ God is $F>$ with any logical, mathematical or "secular" necessary truths does not imply the negation of any logical, mathematical or "secular" necessary truth save as a paradox of strict implication.

(ii) God would be greater if $\mathrm{F}$ than if $\neg$ F. ${ }^{9}$

Roughly, a proposition is secular if it does not say anything about God..$^{10}$ The idea is then presumably that if we consider the property of explaining the modal truths, we will see that it satisfies (i) and (ii). It is supposed to satisfy (i) because the proposition that God explains the modal truths does not (in conjunction with logical, mathematical, or secular necessary truths) entail the negation of any logical, mathematical, or secular necessary truth. And it satisfies (ii) because the relevant instance of (8) is true: God would be greater if God explained the necessary truths than if not. So we are licensed to conclude that the claim that God explains the necessary truths is possible-which is just what we want.

Consider, by contrast, the claim that God does not explain the necessary truths. This will presumably still satisfy (i); but it will not satisfy (ii), because it is not case that God would be greater if God did not explain the necessary truths than if God did. Hence we are not licensed to infer that the claim that God does not explain the necessary truths is possible-which, again, is just what we want. This seems to give us just the asymmetry between NEC and its negation which was lacking in the original argument.

While this proposal is an interesting one, it seems to me not to be of much help in validating the claim that NEC is possible - that it is possible,

${ }^{8}$ See Kripke, Naming and Necessity, Lecture III.

'Leftow, "Perfection and Possibility," 427.

${ }^{10}$ For more details, see Leftow, God and Necessity, 248-251. See also Leftow, “Omnipotence, Evil, and What's In God," 58. I discuss Leftow's more detailed explication of this notion below. 
that is, that God explains the modal truths. There appear to be only two alternatives to the claim that God explains the necessary truths; the first is that they are primitive truths which have no explanation, and the second is that they are explained by something other than God-call this something, whatever it is, $\mathrm{X}$. These propositions might be stated as follows:

BRUTE: The necessary truths are primitive.

NON-GOD: The necessary truths are explained by $\mathrm{X}$.

These both appear to be secular propositions; neither seems to say anything about God. There are exactly two possibilities: either (1) NEC is true and both BRUTE and NON-GOD are false, or (2) NEC is false and one of BRUTE and NON-GOD is true. ${ }^{11}$

Suppose first that (2) is the case. Then it seems that NEC does not in fact satisfy (i). For in this case one of BRUTE and NON-GOD is a secular necessary truth and, as we have just seen, NEC implies the negation of both. So we know that NEC satisfies condition (i) just in case condition (1) obtains - which means that NEC satisfies condition (i) just in case NEC is true. But this is a disaster. We wanted the fact that NEC satisfies conditions (i) and (ii) to give us an argument for its possibility. But, to see that it satisfies these conditions, we have had to employ the premise that it is true. And, of course, if we had that information, we wouldn't need any further argument! We have, it seems, landed right back where we started.

The best move for a proponent of Leftow's view, then, would seem to be to deny that BRUTE and NON-GOD are secular propositions. Let's consider three ways of developing this line of thought.

First, one might say that NON-GOD is not a secular proposition, on the grounds that " $X$ " stands for "something other than God," which surely is about God in some sense. But this would be a bad objection. " $X^{\text {" is not to }}$ be replaced by the description "something other than God." Rather, " $X$ " is to be replaced by a name of the thing (if such there be) which in fact explains the necessary truths. So, for example, it might be replaced by "linguistic conventions" or "the real essences of things." I use the placeholder " $X$ " only because (sadly) I'm not currently in possession of the correct explanation of modal truths. ${ }^{12}$

\footnotetext{
${ }^{11}$ One might think that the claim that the necessary truths are self-explaining provides an alternative to (1) and (2). This is just bookkeeping, but as I intend NON-GOD to be understood, the claim that the necessary truths are self-explaining is an instance of NONGOD - one in which " $X$ " is replaced by "themselves."

${ }^{12}$ One might wonder how this interpretation of NON-GOD squares with the assumption, required by the argument above, that exactly one of the trio of claims (i) NEC, (ii) BRUTE, and (iii) NON-GOD is true. If the " $\mathrm{X}$ " in NON-GOD were an abbreviation for the description "something other than God," then the disjunction of this trio would be a logical truth; but, as just noted, that is not the role of "X." But we can argue for the truth of this disjunction as follows. Either there is some true instance of NON-GOD or there is not. If there is, then the disjunction is true. If there is not, then there is no non-theistic explanation of the modal truths, and at least one of NEC and BRUTE must be true-in which case, again, the disjunction is true. Thanks to Mark Murphy for pointing out the need for clarification on this point.
} 
A second attempt begins with the thought that a truth is non-secular if "none of its terms is apt to express an attribute involving God, attributes only God has, or attributes involving such attributes, unless the term occurs within the scope of a non-factive propositional attitude verb."13 One might then say that the property of explaining the modal truths is an attribute only God has, which would make BRUTE and NON-GOD nonsecular. But in the present context this does not seem like an especially convincing line of reasoning. We are after all in search of a reason to think that NEC is possible. But the claim that explaining the modal truths is a property only God has entails (assuming God's existence) that NEC is true. And if we were already convinced that NEC is true, we would hardly have to take a detour through an account of secular truth to establish its possibility.

A third and perhaps more promising version of the objection would be to say that BRUTE and NON-GOD are not secular because they involve unrestricted quantification. One might then note that God is in the domain of quantification, and say that "any existential quantification quantifying inter alia over God provides information about God if true," 14 and is therefore not secular.

But this would be both mistaken and irrelevant. It would be mistaken, because BRUTE and NON-GOD employ only restricted quantification over the domain of necessary truths - a domain of which God is not a member. It is irrelevant because we can recast the problem in terms of the explanation of specific propositions. Consider, for example, the propositions

The proposition that Hesperus $=$ Hesperus is primitive .

The proposition that Hesperus $=$ Hesperus is explained by $X$.

These are monadic predications which assert claims about what explains a particular proposition. It is hard to see how either could fail to be secular. But, if NEC is false, at least one of them will be true, and so at least one will be a secular necessary truth whose falsity is entailed by NEC. And so again we get the result that NEC satisfies (i) only if true. Hence (i) cannot be used as part of a test of NEC's possibility. ${ }^{15}$

\footnotetext{
${ }^{13}$ Leftow, God and Necessity, 250.

${ }^{14}$ Leftow, God and Necessity, 250-251. However, see Leftow, "Perfection and Possibility," 58 for some qualifications.

${ }^{15} \mathrm{~A}$ possible move here would be to say that "is primitive" is just shorthand for "has no explanation," and that the claim that a certain proposition has no explanation is the negation of an unrestricted universally quantified claim, and hence not secular. But it seems to me that there are two problems with this move. First, we could replace "is primitive" with, e.g., "is fundamental," which seems less likely to be analyzable in terms of absence of explanation. Second, it is only halfway to a solution, since we are still left with the conclusion that the theist who is a proponent of a non-theistic explanation of modal truth will be unmoved by Leftow's reasoning. See below for some further problems with the view that all claims which employ unrestricted quantification are non-secular in this context.
} 
This shows, I think, that Leftow's attempt to use perfect being reasoning to show that NEC is possible, and hence true, does not succeed. But I should note two limitations of my argument to this point.

The first is that none of this is an objection to the truth of Leftow's claim that any proposition satisfying (i) and (ii) must be possible. For all I have said, this claim is true. The problem is rather that we cannot see whether NEC satisfies (i) and (ii) without first knowing whether it is true-which of course makes it useless as a test of NEC's possibility.

The second is that while I have argued that Leftow's conditions don't help us to decide whether NEC is possible, I have not shown that they won't help us in the case of any proposition. Perhaps there are some propositions about God which can be seen to satisfy (i) and (ii) without first determining their truth.

\section{The Problem of Conceivable but Impossible Propositions about God}

So I turn now to a more general worry about the idea that a proposition is possible if it satisfies (i) and (ii). The worry is quite similar to one which, as I argued in "The Method of Perfect Being Theology," arises for many versions of the view that God is the greatest conceivable being. That worry is that, if conceivability (in the theorist's favored sense) does not immediately entail possibility, then there may be hypotheses which would make God greater if true than if not, but which are in the end impossible. So, for example, suppose that it is in the relevant sense conceivable that Hesperus $\neq$ Phosphorus. Then it will also be in the relevant sense conceivable that

VENUS: God could have made it the case that Hesperus $\neq$ Phosphorus.

Would VENUS's truth make God greater than its negation? It is quite plausible that it would; if Venus is true, then God has a certain power, and if it is false, then God lacks that power. All else equal, then, it appears that God is greater if VENUS is true than if $\neg$ VENUS is true. ${ }^{16}$ This is no worry for the proponent of thesis (1), which says that God is the greatest possible being; she can simply point out that VENUS is impossible, and hence that it does not follow from the claim that God is the greatest possible being, plus the fact that God would be greater if VENUS than if $\neg$ VENUS, that VENUS is true. The property of making VENUS true is, after all, an impossible property.

But the case is not so easily handled by the proponent of the view that God is the greatest conceivable being, which does appear to entail the truth of VENUS. And that amounts to a reductio of the thesis that God is the greatest conceivable (in the relevant sense) being.

The example of VENUS is no problem for Leftow; it implies the falsity of the (presumably secular) necessary truth that, necessarily, Hesperus =

${ }^{16}$ The "all else equal" bit is crucial here; many think that God lacks the power to do evil, on the grounds that it is impossible to have this power while being essentially perfectly good, and that it is greater to be essentially perfectly good and lack this power than to have it. 
Phosphorus, and hence does not satisfy (i). But trivial variants of VENUS do make trouble. Consider, for example the claim that

God could have made it the case that something is red and uncolored.

We presumably want this not to come out as possible. But it looks like it will satisfy (i), since, while it does falsify the necessary truth that nothing is red and uncolored, this proposition involves unrestricted quantification and hence is not secular. ${ }^{17}$ I can't think of any secular necessary truths which it does falsify, and it certainly falsifies no logical or mathematical truths. ${ }^{18}$ And the same considerations which make it plausible that VENUS satisfies (ii) make it plausible that this proposition does.

It is not clear that this sort of argument is decisive; perhaps the definition of secular truth could be massaged in such a way as to avoid this sort of problem. I think that this is unlikely. Attempts to construct philosophical theories around a division between propositions of one type and propositions of another usually end in tears. (See: verificationism; the factvalue distinction.) I think that the attempt to define a class of secular truths which can do the relevant work in a theory of possibility is likely to meet the same fate. But that pessimistic conclusion is not entailed by anything I've said here. The idea that we can use perfect being reasoning as a test for possibility is an intriguing one, and worthy of further exploration. ${ }^{19}$

University of Notre Dame

\section{References}

Bohn, Einar Duenger. 2014. “Divine Contingency.” European Journal of Philosophy of Religion 6: 24-31.

${ }^{17}$ Leftow, in reply to Bohn ("Divine Contingency," n7), does qualify the view that all truths involving unrestricted quantification are non-secular. He suggests that "a universally quantified truth is non-secular just if absolute generality is integral to its content" ("Omnipotence, Evil, and What's In God," 58). While I'm not sure exactly what Leftow has in mind (he offers the idea only as a first pass at a satisfactory theory), it does seem to me that absolute generality is integral to the content of the proposition that something is red and uncolored. It seems, at least, to be an essential property of the proposition. Of course there are closely related propositions which lack absolute generality; but the same can be said for any quantified proposition.

${ }^{18}$ The sentence "Nothing is red and uncolored" is of the form "Nothing is F and not-G," which is not a logical truth. Leftow might reply here by modifying condition (i) in his test for possibility by replacing of "falsifies no logical or mathematical truths" with "falsifies no logical, mathematical, or analytic truths," where analytic truths are those which are transformable into logical truths by substituting synonyms for synonyms. But even that won't help here, since "Nothing is red and uncolored" is not analytic. (If you think that it is, then we could switch the example to one of color incompatibilities, which are a priori and necessary but pretty clearly not analytic.) Leftow could instead add to condition (i) "falsifies no a priori truths" or "falsifies no necessary truths," but this would trivialize, and hence render useless, the proposed test for possibility.

${ }^{19}$ Thanks for helpful comments on an earlier draft of this paper to Brian Leftow, Mark Murphy, and a discussion group at the Notre Dame Center for the Philosophy of Religion. 
Kripke, Saul. 1972. Naming and Necessity (Harvard University Press). doi: https://doi.org/10.1007/978-94-010-2557-7_9

Leftow, Brian. 2012. God and Necessity (Oxford University Press). doi: https://doi.org/10.1093/acprof:oso/9780199263356.001.0001

Leftow, Brian. 2014. "Omnipotence, Evil, and What's In God." European Journal of Philosophy of Religion 6: 39-63.

Leftow, Brian. 2015. "Perfection and Possibility." Faith and Philosophy 32: 423-431. doi: https://doi.org/10.5840/faithphil201592848

Speaks, Jeff. 2014. "The Method of Perfect Being Theology." Faith and Philosophy 31: 256-266. doi: https://doi.org/10.5840/faithphil201481315 